\title{
INTERthesis
}

\section{A RADICALIDADE TRANSFORMADORA DA DIFERENÇA. UMA LEITURA SITUADA DE ALGUNS TEXTOS DO FEMINISMO ITALIANO ${ }^{1}$}

Mariateresa Muraca²

Rosanna $\mathrm{Cima}^{3}$

\section{Resumo}

O artigo propõe uma leitura de alguns textos das feministas italianas principalmente de Carla Lonzi e das filósofas da Comunidade Diotima -, com o intuito de argumentar em favor de uma compreensão da diferença feminina aberta e radicalmente transformadora.

Palavras-chave: Carla Lonzi. Diotima. Feminismo. Diferença.

\section{PREMISSAS: DE ONDE ESCREVEMOS}

Este artigo baseia-se em uma proposta de diálogo entre diferentes. Primeiramente o diálogo envolve as autoras, mulheres de gerações diversas e de várias procedências geográficas, que se encontraram num certo ponto de suas trajetórias de vida e que, na reflexão comum, colocam em jogo interesses e posicionamentos nem sempre convergentes. Além disso, os esforços que orientam a escrita concernem à possibilidade de estabelecer uma comunicação entre alguns textos do feminismo italiano da diferença - uma perspectiva encarnada em práticas políticas e localizada em contextos específicos - com interlocutoras e interlocutores de outros lugares, principalmente brasileiros. Que relevância pode ter um feminismo branco e europeu em relação aos desafios que atravessam a realidade brasileira? Quais os riscos de confirmar os rumos consolidados da "geopolítica do

\footnotetext{
${ }^{1}$ Agradecemos ao Prof. Selvino Assmann por ter encorajado muito a elaboração desse artigo, pelas sugestões em relação aos conteúdos e pela revisão das traduções. Agradecemos também a Daniele Manfrini pela colaboração na revisão.

2 Doutora em em Ciências da Educação e da Formação Contínua pela Università degli Studi di Verona, Itália, em co-tutela com a Universidade Federal de Santa Catarina (Programa de PósGraduação Interdisciplinar em Ciências Humanas), Florianópolis, SC, Brasil. E-mail: mariateresa.muraca@univr.it

${ }^{3}$ Doutora em Educação pela Università degli Studi di Verona, Itália. Professora adjunta de Pedagogia da Mediação Cultural, Educação de Adultos e Pedagogia Sanitária na Università degli Studi di Verona, Verona, Itália. E-mail: rosanna.cima@univr.it
} 
conhecimento" (MIGNOLO) 4 que apresenta esta tentativa de criar conexões de pensamento? São perguntas essenciais que nos guiam e nos interrogam no decorrer da elaboração deste artigo.

Por outro lado, é importante situar as cincunstâncias nas quais surgiu o desejo de nos propormos a uma leitura de alguns temas do feminismo italiano. A circunstância é um percurso político e de pesquisa que envolveu uma de nós junto ao Movimento de Mulheres Camponesas (MMC). O MMC surgiu em Santa Catarina em 1983 com o nome de Movimento de Mulheres Agricultoras e se consolidou como movimento nacional em 2004, interligando organizações de diferentes estados do Brasil. Em particular a pesquisa de doutorado realizada por Mariateresa com o MMC em Santa Catarina, de 2011 até 2015, focava as práticas pedagógicas do movimento, com atenção específica às práticas agroecológicas e seus desdobramentos educativos em um sentido feminista e decolonial. Nos últimos anos, de fato, a agroecologia se firmou como o núcleo central das lutas do MMC, se articulando, no interior do movimento, com uma crescente consciência e autoidentificação feminista.

Ao longo do caminho da pesquisa, foi possível observar que as militantes envolvidas evocavam a diferença sexual para motivar o compromisso das mulheres com a agroecologia. A interpretação destas práticas discursivas como expressão tout court de uma posição essencialista - interpretação prevalente por parte de estudiosas sobre o MMC/SC -, todavia, parecia-nos não captar a dimensão desconstrutiva dos papéis sociais femininos, presente nas lutas e na mística do MMC/SC e, sobretudo, nas trajetórias de vida de suas militantes (MURACA, 2015). A preocupação em valorizar adequadamente essas rupturas e a consciência de que as teorias funcionam como "óculos filtrantes" (CIMA, 2012), que frequentemente negam o acesso a importantes níveis da realidade, motivaram a busca por perspectivas que fundamentassem uma visão complexa, processual e transformadora da diferença. Nesta ótica, se revelaram muito férteis algumas ferramentas teóricas do feminismo italiano da diferença, um pensamento com um preciso lugar de enunciação e não hegemônico no panorama global dos feminismos.

${ }^{4}$ Disponível em www.ram-wan.net

R. Inter. Interdisc. INTERthesis, Florianópolis, v.12, n.2, p.246-261, Jul-Dez. 2015 
Em seguida apresentamos uma leitura dos textos de algumas feministas italianas - especialmente de Carla Lonzi e das filósofas de Diotima -, focando em particular a questão da diferença feminina.

\section{CARLA LONZI: A DIFERENÇA COMO PRINCÍPIO EXISTENCIAL}

Carla Lonzi é provavelmente a pensadora feminista frente à qual as múltiplas almas do feminismo italiano reconhecem unanimemente uma dívida (ZAMBONI, 2014). Nascida em Florença em 1931, morreu aos 51 anos. A partir dos anos setenta se dedicou integralmente ao feminismo, abandonando uma brilhante carreira como crítica de arte. Junto com Carla Accardi e Elvira Banotti fundou o coletivo "Rivolta Femminile" (Revolta Feminina) e uma editora ligada ao grupo: "Scritti di Rivolta Femminile" (Escritos de Revolta Feminina).

O Manifesto di Rivolta Femminile ${ }^{5}$ (LONZI, 2010), caracterizado por frases breves e incisivas, expressa a consciência da opressão sexista, conduzida com o auxílio de todo tipo de ideologia - do cristianismo como do marxismo - e por meio de explicações baseadas tanto na natureza quanto na cultura. Ao mesmo tempo, afirma a convicção de que a libertação das mulheres não pode acontecer através da imitação do modelo masculino. "Libertar-se para a mulher não significa aceitar a mesma vida do homem - o que é insuportável - mas expressar o seu próprio sentido da existência"6 (lbid., p.6; tradução nossa).

Nesse sentido, a diferença feminina não é compreendida como um conjunto de traços que caracterizam a especificidade das mulheres em contraposição ou complementarmente ao homem, mas sim como um princípio existencial, baseado no exercício da liberdade. A diferença envolve as maneiras do ser humano, a peculiaridade de suas experiências e do seu sentido da existência. Essa é a ideia central que fundamenta a perspectiva do feminismo praticado por Rivolta Femminile e que retorna em vários escritos elaborados por Carla Lonzi individualmente ou com a Rivolta Femminile. Em Assenza della donna dai momenti celebrativi della

\footnotetext{
${ }^{5}$ Manifesto de Revolta Feminina.

${ }^{6}$ Liberarsi per la donna non vuol dire accettare la stessa vita dell'uomo perché è invivibile, ma esprimere il suo senso dell'esistenza.
}

R. Inter. Interdisc. INTERthesis, Florianópolis, v.12, n.2, p.246-261, Jul-Dez. 2015 
manifestazione creativa maschile ${ }^{7}$ (Ibid.) a diferença é tratada com respeito ao plano criativo, como necessidade da mulher de buscar a autonomia dos padrões criativos definidos historicamente pelo homem.

Em Sputiamo su Hegel${ }^{8}$ (Ibid.), por outro lado, a diferença feminina é afirmada em relação ao paradigma de libertação. Carla Lonzi explicita que escreveu o livro porque se sentia incomodada com a constatação de que a maioria das feministas italianas dava mais crédito à luta de classes do que à própria opressão sofrida como mulheres. É preciso lembrar que naquele momento existia na Itália o maior partido comunista do Ocidente (PCl); além disso, o movimento estudantil de 1968 tinha oferecido às mulheres uma ocasião importante de encontro e participação. Em relação a estas experiências, Rivolta Femminile coloca a necessidade da autonomia feminista, escolhendo o caminho da separação das organizações masculinas e mixtas.

Em particular, em Sputiamo su Hegel (Ibid.), Carla Lonzi declara que a concepção marxista ignora a mulher como oprimida e como portadora de futuro, porque se baseia em um esquema - a dialética do senhor e do escravo - que identifica uma luta interna ao mundo masculino, orientada para a conquista do poder. Esse esquema, de fato, não pode ser aplicado ao conflito entre os sexos por causa da impossibilidade de uma solução que elimine o outro. A recusa da dialética do senhor e do escravo como dispositivo explicativo da opressão sexista e do processo de sua superação traz algumas importantes consequências: primeiramente, problematiza a assunção de uma postura antagonista por parte da mulher, sendo que as exigências que ela explicita não se desenvolvem em antítese ao mundo masculino, mas se movem para outro plano; - além disso, provoca o abandono do objetivo da tomada do poder. "O colocar-se da mulher não implica sua participação no poder masculino, mas um questionamento do próprio conceito de poder"9 (Ibidem, p. 14; tradução nossa). A recusa da luta pelo poder introduz um elemento de ruptura na continuidade do pensamento masculino e a possibilidade de superar o impasse no qual o mundo está paralisado.

\footnotetext{
${ }^{7}$ Ausência da mulher nos momentos celebrativos da manifestação criativa masculina.

${ }^{8}$ Cuspamos em Hegel.

9 II porsi della donna non implica una partecipazione al potere maschile, ma una messa in questione del concetto di potere.
}

R. Inter. Interdisc. INTERthesis, Florianópolis, v.12, n.2, p.246-261, Jul-Dez. 2015 
A busca da independência da mulher e a superação do seu vínculo com o mundo masculino estão profundamente ligadas à prática da autoconsciência introduzida na Itália por Rivolta Femminile, a partir da experiência das feministas norte-americanas. Em Significato dell'autocoscienza nei gruppi femministi"10 (Ibid.), esclarece-se que a autoconsciência possibilita às mulheres se assumirem como sujeitos e seres humanos completos, para além do mito da realização de si através da união amorosa com seu opressor. Neste sentido "o feminismo começa quando a mulher busca a ressonância de si na autenticidade das outras, porque compreende que a única forma de reencontrar a si mesma, é no interior de sua própria espécie ${ }^{11}$ " (Ibid., p.120; tradução nossa). Essa passagem revela a possibilidade da ação criativa feminista e abre para horizontes desconhecidos.

Particularmente La donna clitoridea e la donna vaginale ${ }^{12}$ (Ibid.) manifesta uma nova compreensão, fruto da autoconsciência. Nesse texto, Carla Lonzi questiona muitos mitos sobre a sexualidade feminina, criados pela projeção masculina e frequentemente baseados em uma visão binária, que contrapõe a passividade, a receptividade, a monogamia da mulher ao ativismo, à agressividade $\mathrm{e}$ à poligamia do homem. Na verdade, esses mitos são sustentáveis somente no interior de um modelo sexual baseado no prazer vaginal, que "não é o mais profundo e completo para a mulher, mas é o prazer oficial da cultura sexual patriarcal"13 (Ibid., p.82; tradução nossa). De fato, a vagina é uma zona moderadamente erógena que se tornou o sexo feminino por excelência só por causa da sua complementaridade ao sexo do homem. Neste sentido, o coito é o "primeiro ato de violência e disparidade hierárquica entre os seres"14 (Ibid., p.100; tradução nossa). Ao contrário, o amor clitoriano é assumido - na relação heterossexual como na homossexual como expressão de uma sexualidade feminina autêntica e autônoma, desprendida das ilusões emotivas da integração com o outro, não subjugada à autoridade patriarcal e não vinculada à procriação.

\footnotetext{
10 Significado da autoconsciência nos grupos feministas.

11 II femminismo ha inizio quando la donna cerca la risonanza di sé nell'autenticità di un'altra donna perché capisce che il suo unico modo di ritrovare se stessa è nella sua specie.

${ }^{12}$ A mulher clitoriana e a mulher vaginal.

13 "Il piacere vaginale non è per la donna il piacere più profondo e completo, ma è il piacere ufficiale della cultura sessuale patriarcale".

14 "Primo atto di violenza e di disparità gerarchica tra gli esseri".
}

R. Inter. Interdisc. INTERthesis, Florianópolis, v.12, n.2, p.246-261, Jul-Dez. 2015 
Este último elemento inspira as reflexões de Carla Lonzi sobre o aborto, contidas também em Sessualità femminile e aborto ${ }^{15}$ (Ibid.). Este texto foi escrito em um momento em que os coletivos feministas italianos estavam comprometidos com a discussão sobre $o$ aborto ${ }^{16} \mathrm{e}$ a partir de uma postura que recusava as grandes manifestações como instrumento principal da luta feminista. Para Rivolta Femminile, a autonomia das mulheres não pode ser conquistada através de uma lei concedida pelo poder masculino. Portanto, o grupo se distancia da reivindicação de medidas legislativas específicas, que entreguem o corpo da mulher ao controle do Estado, e aponta para o caminho da despenalização do aborto. Aliás, vai mais a fundo, propondo uma desmistificação feminista do aborto. Segundo Carla Lonzi (Ibid.), de fato, o aborto, mais do que uma expressão da liberdade feminina, é a confirmação de um modelo sexual patriarcal, no qual não existe garantia de prazer para a mulher. "Acontece que a mulher é fecundada no mesmo momento em que the é subtraído seu gozo sexual específico"17 (p.56; tradução nossa). Mais uma vez, a autora insiste na necessidade de uma sexualidade feminina livre: "a natureza nos doou um órgão distinto da procriação [...] é na base disso que nós encontraremos nossa autonomia do homem como nosso senhor"18 (Ibid., p.55; tradução nossa).

Com base na prática da autoconsciência, então, os textos de Rivolta Femminile resgatam a diferença feminina da confusão que a identifica com o próprio êxito da opressão sexista. A diferença não coincide com uma a-histórica "natureza feminina", simétrica e complementar à masculina. Pelo contrário, tem um sentido radicalmente subvertedor do status quo, que as palavras de Carla Lonzi evidenciam com muita eficácia: "esta é a posição do diferente que quer realizar uma mudança global da civilização que o enclausurou. [...] Reconhecemos a nós mesmas a capacidade de fazer deste instante uma modificação total da vida"19 (Ibid., p.15 e 47; tradução nossa). Assim, se do ponto de vista jurídico, a igualdade é um princípio irrenunciável, em relação ao qual todo ser humano deve ter justiça, do ponto de vista

\footnotetext{
15 Sexualidade feminina e aborto.

${ }^{16}$ A norma sobre a interrupção voluntária de gravidez será efetivada em 1978.

17 "Accade alla donna di restare fecondata nel momento stesso in cui le viene sottratto il suo specifico godimento sessuale".

18 "La natura ci ha dotate di un organo sessuale distinto dalla procreazione e (...) è sulla base di questo che noi troveremo la nostra autonomia dall'uomo come nostro signore".

19 "Questa è la posizione del differente che vuole operare un mutamento globale della civiltà che l'ha recluso [...] Riconosciamo a noi stesse la capacità di fare di questo attimo una modificazione totale della vita".
}

R. Inter. Interdisc. INTERthesis, Florianópolis, v.12, n.2, p.246-261, Jul-Dez. 2015 
existencial, ela representa a oferta feita às colonizadas com o intuito de perpetuar sua submissão:

A diferença da mulher são milhares de anos de ausência da história. Aproveitamos da diferença: uma vez completada a integração da mulher, quem pode dizer quantos milhares de anos seriam necessários para arrancar esse novo jugo? Não pensemos em ceder para outros a função de subverter o ordenamento da estrutura patriarcal20 (Ibidem, p.15; tradução nossa).

Para além dos textos aqui brevemente examinados, Carla Lonzi é autora de vários outros livros, entre os quais "Taci anzi parla. Diario di una femminista"21; "Vai pure. Dialogo con Pietro Consagra"22; "Scacco ragionato"23; "Armande sono io!"24; "Autoritratto"25. Buttarelli (2010) evidencia que os escritos de Carla Lonzi e de Rivolta Femminile têm o

Andamento e aquela lógica especial que qualificam as políticas verdadeiramente proféticas, porque mostram o que pode acontecer ou o que está acontecendo e que é ignorado pelas maiorias das pessoas, mas oferecerm também as práticas necessárias para acompanhar o nascimento do "novo" na história ${ }^{26}$ (p.1049; tradução nossa).

De fato, as questões propostas por Rivolta Femminile se firmaram como referências fundamentais para as múltiplas direções do feminismo italiano. Em seguida, examinaremos especialmente as reflexões que, a partir deste ponto de vista, foram desenvolvidas pelas autoras de Diotima.

\section{DIOTIMA: A APOSTA POR UM SENTIDO LIVRE DA DIFERENÇA FEMININA}

Diotima é uma Comunidade Filosófica Feminina, nascida na Universidade de Verona em 1983. Junto com a Biblioteca das Mulheres de Milão é um lugar fundamental de elaboração do pensamento italiano da diferença. "Diotima" não é o

\footnotetext{
20 "La differenza della donna sono millenni di assenza dalla storia. Approfittiamo della differenza: una volta riuscito l'inserimento della donna chi può dire quanti millenni occorrerebbero per scuotere questo nuovo giogo? Non pensiamo a cedere ad altri la funzione di sommuovere l'ordinamento della struttura patriarcale".

${ }^{21}$ Cala aliás fala. Diário de uma feminista.

22 Pode ir. Diálogo com Pietro Consagra.

${ }^{23}$ Xeque-mate ponderado.

${ }^{24}$ Armande sou eu.

${ }^{25}$ Autorretrato.

26 'L'andamento e quella speciale logica che qualificano le politiche veramente profetiche, poiché mostrano ciò che può avvenire o sta avvenendo ed è ignorato dai più, ma offrono anche le pratiche necessarie per accompagnare la nascita del "nuovo" nella storia".
}

R. Inter. Interdisc. INTERthesis, Florianópolis, v.12, n.2, p.246-261, Jul-Dez. 2015 
nome próprio de um grupo, mas o nome comum de uma prática de relação entre mulheres ("Presentazione") ${ }^{27}$. De fato, durante sua história de mais de trinta anos, contribuiram com Diotima muitas mulheres de várias idades, externas ou internas à universidade, mas que têm em comum o desejo de "serem mulheres e pensar filosoficamente", quebrando as supostas neutralidade e universalidade do discurso filosófico (Ibid.). Diotima é autora de treze livros coletivos, que exploram temas originais como: a ordem simbólica materna, a língua materna, a autoridade feminina, o saber da experiência, a distinção entre poder e política ${ }^{28}$, a política do simbólico, o trabalho do negativo (Ibid.). Os pontos de referência fundamentais para Diotima são o pensamento de Luce Irigaray e as práticas teórico-políticas do movimento das mulheres. Entre outras influências importantes, é possível perceber os traços da reflexão de Carla Lonzi.

A aposta por um sentido livre da diferença feminina, central no fazer filosófico de Diotima, é radicada na prática política do "partir de si mesma" (partire da sè) uma prática que finca suas raízes na experiência dos grupos de autoconsciência e na "urgência de reverter o tenaz costume feminino de se pensar a partir do outro de si, ou melhor, de acolher uma imagem do sujeito feminino, traçada no interior de um esquema de 'secundariedade': uma qualificação em termos funcionais em relação à identidade masculina"29 (SARTORI, 1996, p.23; tradução nossa). Como esclarece Zamboni (1996), se bem que na cultura dominante é previsto que as mulheres falem de suas vivências, geralmente esta prática permanece circunscrita à esfera da subjetividade e em um âmbito pré-político. Ao contrário, se for assumida conscientemente, a prática de partir de si mesma transforma radicalmente a política, orientando-se - mais do que para a mudança do mundo em si - para a modificação de si mesma no mundo e da própria relação com o mundo, de acordo com um caminho necessariamente experimental e pessoalmente arriscado. Nas palavras de Muraro (1996), o valor fundamental dessa prática reside no fato de que não fixa as mulheres e os homens que com ela se comprometem nos lugares onde os outros

\footnotetext{
27 Disponível em www.diotimafilosofe.it

${ }^{28}$ Esse tema foi objeto em particular do livro "Potere e politica non sono la stessa cosa", resenhado em Revista de Estudos Feministas por Muraca.

29 "Urgenza di rovesciare la tenace abitudine femminile di pensarsi a partire da altro da sé, o meglio ad accogliere un'immagine del soggetto femminile tracciata all'interno di uno schema di 'secondarietà': una qualificazione in termini di funzionalità rispetto all'identità maschile".
} 
acreditam encontrá-los: isto é, ela não se baseia nos papéis já previstos ou nas situações codificadas, naquilo que se considera justo ou válido, mas expressa a perspectiva de estar no mundo em fidelidade a si mesma, acompanhando transformações, buscas e movimentos do desejo.

A partir desses apontamentos, se compreende que a centralidade da diferença no pensamento de Diotima não coincide com a exaltação dos atributos e dos valores impostos às mulheres pelo patriarcado. O pensamento ocidental, já na antiga Grécia e especialmente a partir da época moderna, dividiu o mundo em duas esferas: uma superior e simbolicamente masculina, pública, livre, ligada à cultura e à política, centrada na produção e no trabalho espiritual; a outra inferior e simbolicamente feminina, privada, dependente, confinada na natureza e no prépolítico, dedicada à reprodução e ao trabalho doméstico (PRAETORIUS, 2011). O banimento da mulher da vida política foi acompanhado pela assunção do seu fundamento nutritivo (SARTORI, 2007). Desta forma, o patriarcado construiu uma verdadeira mitologia da função feminina, associando-a ao papel de garantir - em uma obra geralmente invisível - a vida de homens que se percebiam como independentes (PRAETORIUS, 2011). A problematização desta ordem bipartida que desconheceu e funcionalizou as atividades das mulheres - representou um ponto crucial das análises e das lutas feministas (SARTORI, 2004) e caracteriza também a reflexão de Diotima:

Eu tive, de fato, a impressão de que o grande consenso encontrado pelas
teses da ética do cuidado, apresentada como ética do feminino, estivesse
no fundo ligado a uma valorização de alguns conteúdos peculiares
tipicamente femininos, aliás tradicionalmente femininos, que constituiriam a
substância da diferença, senão a própria diferença. Não contesto aqueles
valores e aqueles conteúdos [...] mas não compartilho a função fundadora
que às vezes parece vir atribuída a estes. A questão não é a avaliação
positiva ou não positiva de um conteúdo que muitas mulheres, até quase
todas, mostram compartilhar. Aquele conteúdo ou aquele fim pode ser até
capaz de movimentar positivamente o reconhecimento ou a adesão por
parte das mulheres, mas querer ligar a liberdade feminina a um conteúdo
particular ou fim determinado, atribuir-lhe inclusive seu valor incluso, isto
sim, seria para citar [...] Kant, pecar de heteronomia ${ }^{30}$ (SARTORI, 1995, p.
28; tradução nossa).

30 "Ho avuto infatti l'impressione che il grande favore incontrato dalle tesi dell'etica della cura, presentata come etica del femminile, fosse in fondo legato a una valorizzazione di alcuni peculiari contenuti tipicamente femminili, e anzi tradizionalmente femminili, che costituirebbero la sostanza della differenza, se non la differenza stessa. Non contesto quei valori e quei contenuti [...] ma non condivido la funzione fondativa che ad essi talvolta pare venir accordata. II punto non è la valutazione positiva o meno di un contenuto che molte donne, fosse anche quasi tutte, mostrano di condividere. Quel contenuto o quel fine sarà anche capace di muovere positivamente il riconoscimento o

R. Inter. Interdisc. INTERthesis, Florianópolis, v.12, n.2, p.246-261, Jul-Dez. 2015 
A recusa de vincular o agir feminino a determinados fins - independemente de sua bondade ou do acordo que muitas mulheres podem manifestar em relação a eles - esclarece a aposta de Diotima por um sentido livre da diferença de ser mulher, que, ao mesmo tempo, não se identifica com o ideal moderno-masculino de liberdade. No paradigma político moderno, de fato, a liberdade é um direito humano universal, baseado no princípio da igualdade entre os homens. A partir desta visão, a conquista da liberdade feminina implica a busca pela igualdade das mulheres com os homens (MURARO, 1995). Esse objetivo está presente, por exemplo, nas políticas em favor da paridade conduzidas nas democracias avançadas para equilibrar os efeitos negativos da exclusão das mulheres dos lugares de poder, segundo um questionamento que, todavia, de acordo com Muraro (Ibid.), não se realiza em um plano substancial, mas apenas no nível da coerência interna do paradigma da modernidade. Dessa forma o feminismo italiano da diferença problematiza profundamente as políticas estatais direcionadas para a integração das mulheres e, em geral, as lutas feministas fundadas exclusivamente na reivindicação de direitos (LIBRERIA DELLE DONNE DI MILANO, 1998).

Esta problematização é evidente, sobretudo, na recusa da luta pelo poder como caminho de libertação válido para as mulheres. A luta pelo poder, de fato, é o elemento de continuidade de uma dinâmica edípica, na qual os filhos destroem a ordem paterna para instituir, no seu lugar, uma nova ordem destinada, por sua vez, a ser revolucionada por novos filhos parricidas e assim por diante (SARTORI, 2009). Em relação à repetição desta história interna ao mundo masculino, Muraro (1995) interpreta, de maneira provocatória, a falta de mulheres nos lugares de poder não como "exclusão", mas como "ausência": "nós começamos a pensar que existe uma ausência feminina que não depende tanto de eventuais exclusões, mas responde sobretudo a uma vontade de não estar ai" ${ }^{11}$ (Ibid., p.127; tradução nossa).

De fato, focalizar a atenção na exclusão significa superestimar a consciência do gesto de quem exclui, privilegiando o ponto de vista do poder, que, todavia, não

l'adesione delle donne, ma voler legare la libertà femminile ad un particolare contenuto o fine determinato, consegnarvi addirittura il suo valore, sarebbe questo sì, per citare [...] Kant, peccare di eteronomia".

31 "Noi cominciamo a pensare che c'è un'assenza femminile che non dipende tanto da eventuali esclusioni, ma risponde piuttosto ad una volontà di non esserci".

R. Inter. Interdisc. INTERthesis, Florianópolis, v.12, n.2, p.246-261, Jul-Dez. 2015 
tem toda a lucidez que se tende a lhe atribuir (Ibid.). A causa principal da ausência feminina, portanto, é devida não ao fato da sua exclusão, mas à unilateralidade do jogo simbólico que acontece nos lugares da disputa pelo poder. Estes não coincidem com os lugares da vida política: aliás, a política os abandona para ir para outros lugares (Ibid.). A partir desta ótica, pode ser compreendida a radical proposta de Buttarelli (2009), que declara a necessidade de "despedir-se definitivamente do crédito que muitas de nós damos às instituições e aos aparatos que definem a democracia representativa [... a partir de] um gesto de coragem e de assunção de responsabilidade para com a nossa diferença e com o mundo que amamos" (p.130; tradução nossa; cursivo no texto) $)^{32}$.

Nesse sentido, no pensamento de Diotima, a diferença sexual não se coloca no espaço de um conflito cujo horizonte está já desenhado, no interior de oposições e polaridades que constituem o próprio tecido da tradição moderno-masculina (TOMMASI, 2002). Pelo contrário, promove um deslocamento - uma "esquiva" nas palavras de Muraro (2009) - que mostra outras possibilidades, gerando e levando ao amadurecimento, os desequilíbrios e as assimetrias simbólicas.

\begin{abstract}
Se trata de abrir do interior do presente, um outro presente, vivo e não repetitivo, gerador de transformações. Porém, para fazê-lo, não basta se contrapor frontalmente, substrair-se ou resistir à realidade presente: é preciso se implicar nela, torná-la experiência em toda sua ambiguidade, sofrê-la e entendê-la com a razão e o sentir sem se adaptar a ela, e a partir do interior encontrar fios que nos mostrem aspectos imprevistos ou em estado emergente ${ }^{33}$ (PIUSSI, 2008; tradução nossa).
\end{abstract}

\title{
4 PALAVRAS FINAIS, INQUIETUDES E DESEJOS
}

No seu posfácio a "Taci anzi parla. Diario di una femminista", Buttarelli (2010) sublinha que a potência transformadora das palavras de Carla Lonzi "chama para si a intuição e rejeita a interpretação"34 (p.1048; tradução nossa). Buscamos permanecer sensíveis a essa observação - que é também uma orientação para a

\footnotetext{
32 "Congedarsi definitivamente dal credito dato da molte di noi alle istituzioni e agli apparati che definiscono la democrazia della rappresentanza [... a partire da] un gesto di coraggio e di assunzione di responsabilità verso la nostra differenza e verso il mondo che amiamo".

${ }^{33}$ Se trata de abrir desde el interior del presente otro presente, vivo y no repetitivo, generador de transformaciones. Pero para hacerlo no basta con contraponerse frontalmente, sustraerse o resistirse a la realidad presente: es preciso implicarse en ella, hacerla experiencia en toda su ambigüedad, sufrirla y entenderla con la razón y el sentir sin adaptarse a ella, y desde el interior encontrar hilos que nos muestren aspectos imprevistos o en estado emergente.

34 "Chiama a sé l'intuizione e respinge l'interpretazione".
}

R. Inter. Interdisc. INTERthesis, Florianópolis, v.12, n.2, p.246-261, Jul-Dez. 2015 
leitura - ao apresentar tanto os escritos de Carla Lonzi quanto os escritos de Diotima. Dessa forma, tentamos mostrar os laços pulsantes do feminismo italiano da diferença com os contextos específicos e as práticas políticas nos quais surgiu, esperando, ao mesmo tempo, suscitar ressonâncias e provocar interrogações nos nossos interlocutores. O percurso político e de pesquisa que nos envolveu nos últimos anos e que explicitamos no começo do artigo nos convida, em todos os nossos esforços teóricos, para um constante exercício de fidelidade às lutas vitais nas quais estamos implicadas. Neste percurso, parece-nos por vezes que possam ser iluminantes os ecos de palavras que vêm de longe, mediatizados por posicionamentos "ex-cêntricos" e consciências fronteiriças. 


\title{
THE TRANSFORMATIVE RADICALNESS OF DIFFERENCE. A SITUATED READING OF SOME ITALIAN FEMINIST TEXTS
}

\begin{abstract}
:
The paper proposes a reading of some Italian feminist texts, mostly from Carla Lonzi and from philosophers of the Diotima Community, in order to argue the understanding of open and radically transforming female difference.
\end{abstract}

Keywords: Carla Lonzi. Diotima. Feminism. Difference.

\section{LA RADICALIDAD TRANSFORMADORA DE LA DIFERENCIA. UNA LECTURA SITUADA DE ALGUNOS TEXTOS DEL FEMINISMO ITALIANO}

Resumen:

El artículo propone una lectura situada de algunos de los textos de las feministas italianas - especialmente de Carla Lonzi y de las filósofas de la Comunidad Diotima con el fin de argumentar a favor de una comprensión de la diferencia femenina abierta y radicalmente trasnformadora.

Palabras clave: Carla Lonzi. Diotima. Feminismo. Diferencia. 


\section{REFERÊNCIAS}

BUTTARELLI, Anna R. Postfazione. In: LONZI, Carla. Taci anzi parla. Diario di una femminista. 2010. Milano: et al., 2010, p.1047-1053.

Sovrane. In: Diotima. Potere e politica non sono la stessa cosa. Napoli: Liguori, 2009, p.127-144.

CIMA, Rosanna. Redesenhar os mapas do encontro: trabalho de cuidado com os migrantes. Visão Global, Joaçaba, v.15, n.1-2, p.103-114, jan./dez., 2012.

DIOTIMA. Presentazione. Disponível em: www.diotimafilosofe.it Acesso em: 12 outubro 2015.

LIBRERIA DELLE DONNE DI MILANO. Non credere di avere dei diritti. La generazione della libertà femminile nell'idea e nelle vicende di un gruppo di donne. Torino: Rosemberg \& Sellier, 1998.

LONZI, Carla. Sputiamo su Hegel e altri scritti. Milano: et. al., 2010.

. Taci anzi parla. Diario di una femminista. Milano: et al., 2010.

. Autoritratto. Milano: et al., 2010.

. Armande sono io! Milano: Scritti di Rivolta Femminile, 1992.

. Scacco ragionato. Milano: Scritti di Rivolta Femminile, 1985.

1980.

Vai pure. Dialogo con Pietro Consagra. Milano: Scritti di Rivolta Femminile,

MIGNOLO, Walter. Geopolítica del conocimiento y diferencia colonial. Disponivél em: www.ram-wan.net Acesso em: 14 setembro 2015.

MURACA, Mariateresa. Práticas populares, feministas e decoloniais do

Movimento de Mulheres em Santa Catarina. Uma etnografia colaborativa. 2015.

R. Inter. Interdisc. INTERthesis, Florianópolis, v.12, n.2, p.246-261, Jul-Dez. 2015 
Tese (Doutorado Interdisciplinar em Ciências Humanas) Centro de Filosofia e Ciências Humanas, Universidade Federal de Santa Catarina, Florianópolis, 2015.

. Diótima, Política e poder não são a mesma coisa. Cadernos Pagu, v. 44, p. 453-461, jan.-jun., 2015.

MURARO, Luisa. La schivata. In: Diotima. Immaginazione e politica. La rischiosa vicinanza tra reale e irreale. Napoli: Liguori, 2009, p. 5-12.

. Partire da sé e non farsi trovare. In: Diotima. La sapienza di partire da sé. Napoli: Liguori, 1996, p. 5-21.

. Oltre l'uguaglianza. In: Diotima. OItre I'uguaglianza. Le radici femminili dell'autorità. Liguori: Napoli, 1995, p. 105-134.

PIUSSI, A. Maria. La sabiduría de quien sabe esquivar la dialéctica entre opresión y libertad. Rizoma freireano - Rhizome freirean, v. 1-2, 2008. Disponível em: www.rizoma-freireano.org Acesso em: 9 setembro 2015.

PRAETORIUS, Ina. Penelope a Davos. Idee femministe per un'economia globale. Milano: Quaderni di Via Dogana, 2011.

TOMMASI, Wanda. Di madre in figlia. In: Diotima. Approfittare dell'assenza. Punti di avvistamento sulla tradizione. Napoli: Liguori, 2002, p.7-25.

SARTORI, Diana. Indizi terrestri. In: Diotima. Potere e politica non sono la stessa cosa. Napoli: Liguori, 2009, p. 15-52. 2007, p. 33-64.

Con lo spirito materno. In: Diotima. L'ombra della madre. Napoli: Liguori, . Donne e uomini tra pubblico e privato. Annali di studi religiosi, Trento, n.5, p. 367-388, 2004.

Nessuno è autore della propria storia: identità e azione. In: Diotima. La sapienza di partire da sé. Napoli: Liguori, 1996, p. 23-57. 
"Tu devi" un ordine materno. In: Diotima. Oltre l'uguaglianza. Le radici femminili dell'autorità. Napoli: Liguori, 1995, p.5-29.

.Tu devi" un ordine materno. In: Diotima. OItre I'uguaglianza. Le radici femminili dell'autorità. Napoli: Liguori, 1995, p.5-29.

ZAMBONI, Chiara. Femminismo sempre scomodo: Carla Lonzi. Introduzione ai testi. Per amore del mondo, n.13, 2014. Disponível em: www.diotimafilosofe.it Acesso em: 30 setembro 2015.

II materialismo dell'anima. In: Diotima. La sapienza di partire da sé.

Napoli: Liguori, 1996, p. 155-170.

Artigo:

Recebido em 17 de Outubro de 2015

Aceito em 13 de Novembro de 2015

R. Inter. Interdisc. INTERthesis, Florianópolis, v.12, n.2, p.246-261, Jul-Dez. 2015 